Originally published as:

Mugisha, L., Pauli, G., Opuda-Asibo, J., Joseph, O., Leendertz, F. and Diedrich, S. (2010), Evaluation of poliovirus antibody titers in orally vaccinated semi-captive chimpanzees in Uganda. Journal of Medical Primatology, 39: 123-128.

DOI: 10.1111/j.1600-0684.2010.00400.x

This is an author manuscript.

The definitive version is available at: http://onlinelibrary.wiley.com 


\title{
Evaluation of poliovirus antibody titers in orally vaccinated semi-captive chimpanzees in Uganda
}

\author{
L. Mugisha ${ }^{1,2}$, G. Pauli ${ }^{3}$, J. Opuda-Asibo ${ }^{2}$, O.O. Joseph ${ }^{3}$, F.H. Leendertz ${ }^{4}$ \& S. Diedrich ${ }^{4}$ \\ ${ }^{1}$ Chimpanzee Sanctuary \& Wildlife Conservation Trust (CSWCT), Entebbe, Uganda \\ ${ }^{2}$ Department of Wildlife and Animal Resources Management (WARM), Faculty of Veterinary Medicine, \\ Makerere University, Kampala, Uganda \\ ${ }^{3}$ College of Health Sciences, School of Biological Science, Department of Microbiology, P.O Box \\ 7072, Kampala, Uganda \\ ${ }^{4}$ Robert Koch-Institut, Nordufer 20, Berlin 13353, Germany
}

Correspondence:

Dr Lawrence Mugisha, Department of

Wildlife and Animal Resources

Management (WARM), Makerere

University, PO Box 7062, Kampala, Uganda.

Tel.: +256 772566551 ;

fax: +256 414321737 ;

e-mail: Imugisha@vetmed.mak.ac.ug

\begin{abstract}
Background: To understand immunological responses in chimpanzees vaccinated with live-attenuated vaccine (oral polio vaccine; OPV), serum neutralizing antibodies against poliovirus types 1,2 , and 3 were investigated over time.

Methods: The neutralizing antibody titers against poliovirus types 1, 2, and 3 were determined by microneutralization test using 100 ID50 of poliovirus types 1, 2, and 3 (Sabin strains).

Results: Neutralizing antibodies against poliovirus types 1, 2, and 3 were detected in $85.7 \%, 71.4 \%$, and $65 \%$ of the serum from 42 chimpanzees tested 9 years post-vaccination. The neutralizing antibody titers in chimpanzees were similar to the documented levels in human studies as an indicator of vaccine efficacy.

Conclusions: This study reveals persistence of neutralizing antibodies in chimpanzees for at least 9 years after vaccination with OPV. This first study in chimpanzees provides useful information for the evaluation of the success of vaccination with OPV in other captive apes.
\end{abstract}

\section{Introduction}

Poliomyelitis is a life-threatening acute paralytic disease caused by poliovirus (PV) $[2,3,19,32,33$, 39]. Poliovirus is highly infectious belonging to the genus Enterovirus in the family Picornaviridae with three distinct serotypes (type 1,2, and 3) [3]. Poliovirus is mainly transmitted through the fecal-oral route as the virus replicates efficiently in the intestinal tract. In humans, it is typically shed with the stool for 2-4 weeks. Feces can serve as a source of contamination of water, milk, and food. Houseflies can passively transfer poliovirus from feces to food [13]. Virus transmission is facilitated by poor sanitation and factors such as crowding, low levels of hygiene, water quality, and sewagehandling facilities. Humans are considered as the sole reservoir for poliovirus. The three serotypes are able to cause human infection with incubation periods of 5-35 days. Poliomyelitis is an acute viral infection, which ranges in severity from a non-specific illness to paralysis with permanent disability and death. Historically, poliovirus paralyzed and killed high numbers of people before the licensing of inactivated poliovirus vaccine (IPV) in 1955 and Oral Polio Vaccine (OPV) in 1962 and introduction of vaccination worldwide [33]. The IPV is prepared by growing the poliovirus in monkey kidney tissue culture (vero cell line) and inactivated with formaldehyde [6]. It contains 2-phenoxyethanol, neomycin, streptomycin, polymyxin B (used to prevent bacterial and fungal growth), and all three serotypes of poliovirus [7]. The vaccine is effective in inducing circulating antibodies in blood, thus preventing polio virus in the gut from entering and replicating in the central nervous system [39]. Whereas trivalent OPV is a live-attenuated vaccine containing all three serotypes of poliovirus in a ratio of 10:1:6 [7, 26]. 
These attenuated PV strains replicate in the human gut inducing mucosal immunity that inhibits replication of the virus in the gastrointestinal tract $[7,26]$. The OPV produces long-lasting mucosal immunity by stimulating the formation of $\lg A$ antibodies in the intestine and also serum antibodies in the bloodstream [35].

Although humans are the only known natural reservoirs of poliovirus, non-human primates, especially apes (chimpanzees and gorillas), are susceptible [10, 11]. Macaques, African green monkeys and Cebus spp. can be experimentally infected with poliovirus but do not generally develop a paralytic disease when infected by the peripheral route [36]. However, paralytic disease

because of poliovirus infections via human contacts has been reported in captive chimpanzees, orangutans, gorillas, and colobus monkeys [1, 3, 10, 17, 20, 21]. Antibodies and shedding of virus have been found in imported animals [10], and some chimpanzees may act as symptomless carriers [4]. A suspected poliovirus outbreak in wild apes was reported in Kasakela Community of the Gombe chimpanzee population research group in Tanzania in 1966 where six chimpanzees died from the disease and at least six others were paralyzed lifelong [14-16, 22]. A similar outbreak among the free-ranging chimpanzees was reported in Beni, Zaire, with at least seven of 48 chimpanzees in the study group handicapped by limb paresis [27]. Analysis of chimpanzee skeletons of two adult females with longterm, partial paralysis and a group of unaffected adult Gombe chimpanzees revealed that poliovirus caused considerable asymmetries in the skeleton [31]. It was not clarified whether the outbreak was part of a natural cycle within the great ape population or a result of poliovirus transmission from humans. Chimpanzees in Gombe National Park $\left(25 \mathrm{~km}^{2}\right)$ inhabit a potentially contaminated environment from human communities living close to the park in the north and south sharing the same resources such as water [16, 37]. Poliovirus was widespread in the local human population during the 1960s and therefore transmission from humans was discussed as the most likely route when the chimpanzee community was habituated for research [22, 37]. Chimpanzees are susceptible to almost all human pathogens, so close proximity increases the risk of disease transmission [28]. Hence, it was recommended that chimpanzees and other apes in captive facilities should be vaccinated against poliovirus to avoid the risk of direct or indirect transmission from humans $[25,38,40]$.

Therefore, primates in sanctuaries are generally vaccinated with the human poliovirus vaccine. However, as yet no long-term studies have been undertaken to evaluate immunological responses in vaccinated apes, and all recommendations on vaccination strategies are based on human studies. The American Zoo and Aquarium Association Species Survival Plan recommend vaccination of captive great apes with IPV at 12-13 months of age with a booster once at 1-2 years $[25,38]$. Captive facilities and sanctuaries in Africa are using OPV in apes following human vaccination schedules, but variable regimes are used. To complement the Global Polio Eradication Program, vaccination programs of non-human primates in sanctuaries have to be adapted to the current state of art.

In this study, we show that OPV induces a long-lasting immunity against poliovirus in sanctuary chimpanzees in Uganda, and we discuss the future use of IPV for the vaccination of non-human primates in captivity. 


\title{
Materials and methods
}

\author{
Study site
}

Ngamba Island Chimpanzee Sanctuary which started in 1998 is located on Ngamba Island (S 000 06/E $32^{\circ} 39,0.46 \mathrm{~km}^{2}, 1160 \mathrm{~m}$ above sea level) and is part of the Koome group of islands in Mukono District, Uganda, lies $23 \mathrm{~km}$ off Entebbe in the northwest of Lake Victoria. Ngamba Island Chimpanzee Sanctuary currently cares for 44 rescued orphan chimpanzees on 100 hectares of secondary rain forest in a semi-captive management system with dietary supplements every day.

\section{Study species}

The study was conducted on 42 orphan chimpanzees that live in a semi-captive management system on Ngamba Island Chimpanzee Sanctuary. The group consisted of 23 females and 19 males with age group categorized as follows: four infants (1-5 years), six juveniles (6-8 years), 12 sub-adults (9-11 years), and 20 adults (12 years and more). They have lived on the island for varying lengths of time after being rescued from illegal traders and poachers since 1998. Rescued individuals are held in quarantine for 90 days during which period they are vaccinated against polioviruses using OPV (0.1 ml of Sabin Polio, Panacea Biotec Ltd, A-241 Okhla Indi.Area-1, Delhi-110020). Routine management of these rescued chimpanzees on the island exposes them to direct human contact by caregivers and veterinarians and indirectly to tourists, school groups, local community members, and researchers. They are fed on locally grown fruits and vegetables purchased from local markets.

\section{Blood collection}

Blood was collected from all chimpanzees during our annual medical checks in February, 2007. Individual animal welfare is of paramount importance and is part of our standard operating procedures; hand-held intramuscular injection of anesthetic drugs using a combination of ketamine (3 mg/kg) and meditomidine $(0.03 \mathrm{mg} / \mathrm{kg})$ is administered to minimize stress. Blood $(7.5 \mathrm{ml})$ was taken from the femoral vein using EDTA Vacutainer tubes. Plasma/serum was extracted by centrifugation and stored at $-80^{\circ} \mathrm{C}$ at the Uganda Virus Research Institute until transported on dry ice to Robert Koch-Institut, Berlin, Germany, for analysis. Retrospective serum collected in 2001 and 2005 and stored at $-40^{\circ} \mathrm{C}$ was included in the assessment of antibody titers. This study was approved by Chimpanzee Sanctuary \&Wildlife Conservation Trust as part of the veterinary preventive healthcare management, and research and export permits were issued by Uganda Wildlife Authority, Uganda National Council of Science and Technology, CITES Office in Uganda and Germany.

\section{Serology}

The methods for the determination of the neutralizing antibody titers against poliovirus types 1,2 , and 3 have been described elsewhere [41]. Briefly, the microneutralization test using 100 ID50 poliovirus (Sabin strains) was performed according to WHO guidelines [41]. A positive control using an in-house reference serum (IHR) of known neutralizing activity was included in each test to control reproducibility of results. The international standard serum (a preparation of pooled human serum) containing $25 \mathrm{IU}$, $50 \mathrm{IU}$, and $5 \mathrm{IU}$ for polioviruses 1, 2, and 3, respectively, was used to calibrate the potency of the IHR [9]. Before laboratory testing, serum was inactivated for 30 minutes at $56^{\circ} \mathrm{C}$ in a water bath. Afterward, twofold dilutions of serum starting from 1:4 to 1:512 were incubated for 3 hours at $36^{\circ} \mathrm{C}$ in duplicate with 100 TCID50 of the corresponding Sabin-type poliovirus. Human rhabdomyosarcoma cell suspensions were added, and results were scored after 7 days of culture. A serum dilution of $\ddagger 1: 4$ giving protection against 100 TCID50 of poliovirus was considered to be positive. 


\section{Results}

The vaccinated chimpanzees with OPV under this study were found with neutralizing antibodies against poliovirus types 1,2 , and 3 detected in $85.7 \%, 71.4 \%$, and $65 \%$, respectively, of the tested serum 9 years post-vaccination. Of the studied chimpanzees, five had no neutralizing antibodies $(<1: 4)$ against poliovirus types 1,2 , and 3 , including the captive-born infant that had not been vaccinated. Percentages for neutralizing antibodies from 2001 to 2005 serum were not computed because of high levels of bacterial contamination in the samples. For non-contaminated serum samples (results not shown here), neutralizing antibody titers were comparable with those obtained from 2007. The three recent orphan arrivals (Kityo, Rutoto and Rambo) had multiple vaccinations (more than three with OPV) while in quarantine as shown in Table 1, but the neutralizing antibodies showed the same trend as those vaccinated once or twice.

\section{Discussion}

We present for the first time a vaccination success of captive chimpanzees with OPV. The neutralizing antibody titers found in chimpanzees are similar to those reported in human studies [9], indicating a high level of protection in the OPV-vaccinated chimpanzees. This study also reveals persistence of neutralizing antibodies for at least 9 years post-vaccination with OPV. The percentage of neutralizing antibodies detected against poliovirus types 2 and $3(71.4 \%$ and $65 \%)$ was generally lower than those for poliovirus 1 (85.7\%). This is in agreement with serological studies in humans, showing lower antibody titers for poliovirus types 2 and $3[8,9]$. Four chimpanzees had no neutralizing antibodies $(<1: 4)$ against poliovirus types 1,2 , and 3 despite records showing they had been vaccinated at least once. This may be because of other viral or helminth intestinal infections prohibiting uptake of OPV as reported in developing countries where OPV has been shown to be less potent in inducing humoral immunity. Repeated vaccinations up to 5-10 times are hence required to protect all children $[23,30$, 32, 34].

It is known that immunity to poliomyelitis is dependent on humoral neutralizing antibodies, both after natural infection and after vaccination. Hence, presence of antibodies beyond a threshold antibody level is an indication of protective immunity in case of poliomyelitis. It has been shown that enterovirus infections also induce T-cell immunity [24], but little information is available about the cellular immunity in great apes. It is not even clear whether these individual chimpanzees with low titers or no detectable antibodies are susceptible to infection as it is with humans.

Trivalent OPV is recommended by Expanded Program on Immunisation as a vaccine of choice for eradication of poliomyelitis because of its low cost, ease of administration, superiority in conferring intestinal immunity, and the potential to infect household and community contacts secondarily [12]. However, it

has been reported that OPV is less potent in inducing humoral immunity in developing countries where the infection of the intestines by other viruses may prohibit the intake of OPV. Further, the continuous use of OPV may result in increase vaccine-associated paralytic polio, circulating vaccine-derived polioviruses (cVDPV) and those originating from immune-deficient vaccine-derived polioviruses (iVDPV) [26, 29]. Therefore, the IPV, which is already widely used in developed countries, should play the major role during the endgame of polio eradication and thereafter.

Hence, poliovirus vaccination of non-human primates, especially apes in captive facilities (zoos and sanctuaries), should be evaluated along with the global eradication program and follow the established WHO global action for laboratory containment of wild polioviruses [42, 43]. This study shows that OPV induces high levels of protective immunity in chimpanzees, but future use of OPV in captive apes should be assessed. As vaccine-derived strains (VDPV) may be excreted in feces for several weeks and even years (in the case of immunodeficient patients), it serves as a source of dissemination of polioviruses and the cause of poliomyelitis $[18,26,29]$. Sequence drift has been shown in VDPV as an indication of prolonged replication of the vaccine strain either in one individual or in the community [5, $26,29]$. Although it is not known for how long the polioviruses are excreted in feces of vaccinated apes, it may be risky to continue to use OPV in apes, and IPV may be safer to use at this point. The results presented in this study will serve as a baseline data for more studies to be undertaken in primates to estimate risks and advantages of OPV vs. IPV vaccinations for great apes in sanctuaries. 


\section{Acknowledgments}

This research was carried out within the network of 'Great Ape Health Monitoring Unit' (GAHMU). The analyses were supported by Robert Koch-Institut, Berlin; Brian Hare, Max-Planck-Institute for Evolutionary Anthropology, Leipzig; and Kim Hammond, Falls Road Hospital, Baltimore, Maryland, through Mountain Gorilla Veterinary Project (MGVP) and DAAD small research grant. We acknowledge the Center for Disease Control (CDC), Uganda, Uganda Virus Research Institute, Uganda, for providing facilities for sample storage and CDC assisting in the shipment of samples.

\section{References}

1 Allmond BW, Froeschle JE, Guilloud NB: Paralytic poliomyelitis in large laboratory primates. Virological investigation and report on the use of oral poliomyelitis virus (OPV) vaccine. Am J Epidemiol 1967; 85:229-39.

2 Bodian D: Poliomyelitis. In: Pathology of the Nervous System, Vol 3. Minckler (ed.). New York: McGraw-Hill, 1972; 2323-44.

3 Bodian D, Morgan IM, Howe HA: Differentiation of types of poliomyelitis viruses. III. The grouping of fourteen strains into three basic immunological types. Am J Hyg 1949; 49:234-45.

4 Brack M: Agents Transmissible from Simians to Man. Berlin: Springer-Verlag, 1987.

5 Cherkasova E, Laassri M, Chizhikov V, Korotkova E, Dragunsky E, Agol IV, Chumakov K: Microarray analysis of evolution of RNA viruses: evidence of circulation of virulent highly divergent vaccine-derived polioviruses. PNAS 2003; 100:9398-403.

6 Centers for disease Control and prevention: Circulation of a type 2 vaccine-derived poliovirus-Egypt, 1982-1993. Morb Mortal Wkly Rep, 2001; 50: 41-51.

7 Centers for disease Control and prevention: Progress toward global eradication of poliomyelitis, 2001. Morb Mortal Wkly Rep, 2002a; 51: 253-6.

8 Conyn-van Spaendonck MA, de Melker HE, Abbink F, Elzinga-Gholizadea N, Kimman TG, Van Loon T: Immunity to poliomyelitis in Netherlands. Am J Epidemiol 2003; 153:207-14.

9 Diedrich S, Claus H, Schreier E: Immunity status against poliomyelitis in Germany: determination of cutoff values in International Units. BMC Infect Dis 2002; 2:1471-2334.

10 Douglas JD, Soike KF, Raynor J: The incidence of polio virus in chimpanzees (Pan troglodytes). Lab Anim Care 1970; 20:265-8.

11 Dowdle WR, Birmingham ME: The biologic principles of poliovirus eradication. J Infect Dis 1997; 175:S286- 92.

12 Expanded Programme on Immunisation: Global advisory Group. Wkly Epidemiol Rec 1991; 66:312.

13 Gear JHS: The extra human sources of poliomyelitis. In: Poliomyelitis Papers and Discussions Presented at the Second International Poliomyelitis Conference. Philadelphia: JB Lippincott, 1952.

14 Goodall J, Van L: Behaviour of free-living chimpanzees of the Gombe Stream area. Anim Behav Monogr 1968; 1:163-311.

15 Goodall J: Population dynamics during a fifteen-year period in one community of free-living chimpanzees in the Gombe National Park, Tanzania. Z Tierpsychol 1983; 61:1-60.

16 Goodall J: The Chimpanzees of Gombe: Patterns of Behavior. Cambridge, Massachusetts: Harvard University Press, 1986.

17 Guilloud NB, Allmond BW, Froeschle JE, Fitz-Gerald FL: Paralytic poliomyelitis in laboratory primates. J Am Vet Med Assoc 1969; 155:1190-3.

18 Hovi T, Lindholm N, Savolainen C, Stenvik M, Burns C: Evolution of wild-type 1 poliovirus in two healthy siblings excreting the virus over a period of 6 months. J Gen Virol 2004; 85:369-77.

19 Hovi T, Blomqvist S, Nasr E, Burns CC, Sarjakoski T, Ahmed N, Savolainen C, Roivainen M, Stenvik M, Laine P, Barakat I, Wahdan MH, Kamel FA, Asghar H, Pallansch MA, Kew OM, Gary HE $\mathrm{Jr}$, deGourville EM, El Bassioni L: Environmental surveillance of wild poliovirus circulation in Egyptbalancing between detection sensitivity and workload. J Virol Methods 2005; 126:127-34.

20 Howe HA, Bodian D: Poliomyelitis by accidental contagion in the chimpanzee. J Exp Med 1944; 80:383-90.

21 Howe HA, Bodian D: Poliomyelitis in the cynomologus monkey following oral inoculation. Am J Hyg 1948; 48:99-106.

22 Huckster RL: Poliomyelitis. A Guide for Developing Countries-Including Appliances and Rehabilitation for the Disabled. NewYork: Churchill Livingstone, 1975.

23 John TJ, Jayabal R: Oral polio vaccination of children in the tropics: the poor seroconversion rates and the absence of viral interference. Am J Epidemiol 1972; 96:263-9. 
24 Juhela S, Hyöty H, Uibo R, Meriste SH, Lönnrot M, Halminen M, Simell O, llonen J: Comparison of enterovirus-specific cellular immunity in two populations of young children vaccinated with inactivated or live poliovirus vaccines. Clin Exp Immunol 1999; 117:100-5.

25 Junge RE: Vaccination Programs: Preventive Medicine Recommendations. American Association of Zoo Veterinarians Infectious Disease Committee, St. Louis, Missouri, 1995.

26 Kew OM, Wright PF, Agol VI, Delpeyroux F, Shimizu H, Nathanson N, Pallansch M: Circulating vaccinederived polioviruses: current state of knowledge. Bull World Health Organ 2004; 82:16-32.

27 Kortlandt A: An epidemic of limb paresis (polio) among the chimpanzee population at Beni (Zaire) in 1964, possibly transmitted by humans. Pan Afr News 1996; 3:2.

28 Leendertz FH, Pauli G, Maetz-Rensing K, Boardman W, Nunn C, Ellerbrok H, Jensen SA, Junglen $\mathrm{S}$, Boesch C: Pathogens as drivers of population declines: the importance of systematic monitoring in great apes and other threatened mammals. Biol Conserv 2006; 131:325-37.

29 Martin J: Vaccine-derived poliovirus from long term excretors and the end game of polio eradication. Biologicals 2006; 34:117-22.

30 Melnick JL: Current status of polio infections. Clin Microbiol Rev 1996; 9:293-300.

31 Morbeck ME, Zihlman AL, Sumner DR, Galloway A: Poliomyelitis and skeletal asymmetry in Gombe Chimpanzees. Primates 1991; 32:77-91.

32 Moriniere BJ, van Loon FP, Rhodes PH, Klein-Zabban ML, Frank-Senat B, Herrington JE, Patriarca PA: Immunogenicity of a supplemental dose of oral versus inactivated poliovirus vaccine. Lancet 1993; 341:1545- 50.

33 Nathanson N, Martin JR: The epidemiology of poliomyelitis: enigmas surrounding its appearance, epidemiology, and disappearance. Am J Epidemiol 1979; 110:672-91.

34 Oduntan SO, Lucas AO, Wennen EM: The immunological response of Nigerian infants to attenuated and inactivated polio vaccines. Ann Trop Med Parasitol 1978; 72:111-5.

35 Pelczar MJ Jr, Chan ECS, Krieg NR: Microbiology: Concepts and Applications. McGraw-Hill, Inc, New York; 1993; 698.

36 Samuel BU, Ponnuraj E, Rajasingh J, John TJ: Experimental poliomyelitis in bonnet monkey. Clinical features, virology and pathology. Dev Biol Stand 1993; 78:71-8.

37 Teleki G, Hunt EE Jr, Pfifferling JH: Demographic observations (1963-1973) on chimpanzees of Gombe National Park, Tanzania. J Human Evol 1976; 5:559-98.

38 Wallis J, Lee DR: Primate conservation: the prevention of disease transmission. Int J Primatol 1999; 20:803-26.

39 Wood DJ, Sutter RW, Dowdle WR: Stopping poliovirus vaccination after eradication: issues and challenges. Bull World Health Organ 2000; 78:347-57.

40 Woodford $\mathrm{MH}$ (Ed.): Quarantine and Health Screening Protocols for Wildlife prior to Translocation and Release into the Wild. IUCN Species Survival Commission's Veterinary Specialist Group, Gland, Switzerland, the Office International des Epizooties (OIE), Paris, France, Care for the Wild, U.K., and the European Association of Zoo and Wildlife Veterinarians, Switzerland, 2000.

41 World Health Organisation: Polio Laboratory Manual (4th edn). WHO/IVB/04.10, 2004.

42 World Health Assembly: Global eradication of poliomyelitis by the year 2000. In: Resolution 41-28

of the $41^{\text {st }}$ World Health Assembly. Geneva, Switzerland: World Health Organization, 1998.

43 World Health Organisation: WHO global action plan for laboratory containment of wild polioviruses. Second edition revised in 2004 and 2008. Geneva: Department of Vaccines and Biologicals. World Health Organization, WHO/V\&B/03.11, 2003. 


\section{Table}

Table 1 Neutralizing poliovirus antibodies from 2007 chimpanzee serum

\begin{tabular}{|c|c|c|c|c|c|}
\hline \multirow{2}{*}{$\begin{array}{l}\text { Chimpanzee } \\
\text { name }\end{array}$} & \multirow[b]{2}{*}{ Sex } & \multirow{2}{*}{$\begin{array}{l}\text { Vaccination } \\
\text { dates }\end{array}$} & \multicolumn{3}{|c|}{ Neutralizing antibodies, 2007} \\
\hline & & & Poliovinus 1 & Poliovinus 2 & Poliovinus 3 \\
\hline Masiko & ${ }^{1} \mathrm{C}$.male & 21.11 .01 & $1: 4$ & $>1: 32$ & $<1: 4$ \\
\hline Robbie & Male & 27.11 .01 & $>1: 32$ & $1: 4$ & $>1: 32$ \\
\hline Tumbo & Male & 21.11 .01 & $>1: 32$ & $>1: 32$ & $>1: 32$ \\
\hline Eddy & Male & 21.11 .01 & $>1: 32$ & $1: 16$ & $1: 8$ \\
\hline Sunday & ${ }^{1}$ C.Male & 27.11 .01 & $>1: 32$ & $>1: 32$ & $1: 16$ \\
\hline Mika & Male & 20.11 .01 & $>1: 32$ & $1: 16$ & $>1: 32$ \\
\hline Megan & Female & 03.10 .01 & $>1: 32$ & $>1: 32$ & $>1: 32$ \\
\hline Kidogo & Female & 26.09 .01 & $>1: 32$ & $>1: 32$ & $>1: 32$ \\
\hline Peace & Female & 21.11 .01 & $>1: 32$ & $>1: 32$ & $1: 16$ \\
\hline Sophie & Female & 26.09 .11 & $>1: 32$ & $>1: 32$ & $1: 8$ \\
\hline Nagoti & Female & 03.10 .01 & $>1: 32$ & $>1: 32$ & $<1: 4$ \\
\hline Katie & Female & 26.09 .01 & $>1: 32$ & $1: 16$ & $>1: 32$ \\
\hline Connie & Female & 26.09 .01 & $>1: 32$ & $>1: 32$ & $<1: 4$ \\
\hline Bahati & Female & 03.10 .01 & $>1: 32$ & $>1: 32$ & $<1: 4$ \\
\hline Natasha & Female & 21.11 .01 & $>1: 32$ & $1: 8$ & $1: 8$ \\
\hline Becky & Female & 27.11 .01 & $>1: 32$ & $1: 16$ & $>1: 32$ \\
\hline Sally & Female & 27.11 .01 & $>1: 32$ & $1: 4$ & $>1: 32$ \\
\hline Cindy & Female & 11.10 .01 & $>1: 32$ & $1: 4$ & $1: 4$ \\
\hline lkunu & Female & 11.10 .01 & $>1: 32$ & $1: 4$ & $<1.4$ \\
\hline Nkumwa & Female & 11.10 .01 & $<1: 4$ & $1: 4$ & $<1: 4$ \\
\hline Billi & Female & 20.11 .01 & $>1: 32$ & $1: 8$ & $1: 4$ \\
\hline Yoyo & Female & 20.11 .01 & $1: 4$ & $<1: 4$ & $<1: 4$ \\
\hline Namukisa & Female & 20.11 .01 & $>1: 32$ & $>1: 32$ & $1: 4$ \\
\hline Pasa & Female & 20.11 .01 & $\mathrm{Ct}$ & 1.8 & $\mathrm{Ct}$ \\
\hline Ndyakira & Female & $23.05 .02 / 30.07 .02$ & $>1: 32$ & $1: 8$ & $1: 16$ \\
\hline Kazahukire & Female & 20.08 .02 & $1: 4$ & $1: 4$ & $<1: 4$ \\
\hline Nakuu & Female & $31.05 .02 / 30.07 .02$ & $>1: 32$ & $\mathrm{Ct}$ & $\mathrm{Ct}$ \\
\hline Nani & Female & 2002 & $1: 8$ & $\mathrm{Ct}$ & $\mathrm{Ct}$ \\
\hline Mawa & Male & 10.11 .01 & $>1: 32$ & $>1: 32$ & $>1: 32$ \\
\hline Kalema & Male & 10.11 .01 & $1: 16$ & $1: 4$ & $>1: 32$ \\
\hline Umutama & Male & 20.11 .01 & $>1: 32$ & $1: 4$ & $1: 8$ \\
\hline Umugezi & Male & 20.11 .01 & $>1: 32$ & $<1.4$ & $>1: 32$ \\
\hline Baluku & Male & 20.11 .01 & $>1: 32$ & $<1.4$ & $>1: 32$ \\
\hline Asega & Male & 10.11 .01 & $>1: 32$ & $>1: 32$ & $<1.4$ \\
\hline Kisembo & Male & 11.10 .01 & $<1.4$ & $<1.4$ & $<1.4$ \\
\hline Indi & Male & 20.11 .01 & $>1: 32$ & $>1: 32$ & $<1: 4$ \\
\hline Okech & Male & $19.04 .02 / 21.05 .02$ & $>1: 32$ & $1: 8$ & $<1.4$ \\
\hline Bwambale & Male & 09.03 .02 & $1: 16$ & $>1: 32$ & $<1: 4$ \\
\hline Kyewunyo & Female & Not vaccinated & $<1.4$ & $<1.4$ & $<1.4$ \\
\hline Kityo & Male & $9 / 06 ; 11 / 06 ; 02 / 07$ & $>1: 32$ & $1: 16$ & $<1: 4$ \\
\hline Rutoto & Male & $06 / 06 ; 08 / 06 ; 02 / 07$ & $>1: 32$ & $1: 8$ & $1: 8$ \\
\hline Rambo & Male & $\begin{array}{r}09 / 06 ; 10 / 06 ; \\
12 / 06 ; 02 / 07\end{array}$ & $>1: 32$ & $>1: 32$ & $<1: 4$ \\
\hline
\end{tabular}

Cutoff at dilution of 1:4 in serum.

${ }^{1}$ Castrated male; Ct: results could not be read because of bacterial contamination. 